\title{
CLINICO-BACTERIOLOGICAL STUDY OF VESICAL CALCULUS
}

\author{
Pushpendra Singh1, Brijesh Singh², Vinod Yedalwar ${ }^{3}$, A. P. S. Gaharwar 4
}

${ }_{13}^{\text {rd }}$ Year Junior Resident, Department of General Surgery, Shyam Shah Medical College, Rewa, Madhya Pradesh.

${ }^{2}$ Assistant Professor, Department of General Surgery, Shyam Shah Medical College, Rewa, Madhya Pradesh.

${ }^{3}$ Associate Professor, Department of General Surgery, Shyam Shah Medical College, Rewa, Madhya Pradesh.

${ }^{4}$ Professor and HOD, Department of General Surgery, Shyam Shah Medical College, Rewa, Madhya Pradesh.

\section{ABSTRACT}

\section{BACKGROUND}

Vesical calculi are the most common manifestation of lower urinary tract lithiasis. Urinary infections play an important role in aetiopathogenesis of vesical calculi.

\section{OBJECTIVE}

Aim of this study was proposed to establish the bacteriology of stone and urine in an attempt to evaluate the role of infection in the formation of stone. Associated factors like age, sex, site of infection, obstruction, diet were also evaluated.

\section{DESIGN}

Prospective cohort study.

\section{METHODS}

The patients were admitted in surgical ward as provisional diagnosed cases of vesical calculus, were subjected to investigations including CBC, RBS, urine analysis, renal function test, x-ray KUB region and ultrasonography. Patients who were fit for surgery, various surgical procedures were done. Gross examination and core culture of stone was done to establish their aetiology.

\section{RESULTS}

Ninety-four patients with vesical calculus were evaluated. Incidence of vesical calculus was 1.13\%. Majority of cases were from rural areas (92.55\%). Urinary tract infection was present in $37.2 \%$ of cases, majority of cases urine culture was positive (30.95\%). Core culture of stone was positive in 18 cases (25.17\%). E. coli was the predominant organism both in urine culture (19.04\%) and core culture of stone $(25.71 \%)$.

\section{CONCLUSIONS}

There is significant association regarding the presence of vesical calculi and the development of urinary infections. E. coli was the predominant organism found both in urine and core culture of stone.

\section{KEYWORDS}

Urolithiasis, Vesical Calculi, Urine Culture, Core Culture of Stone.

HOW TO CITE THIS ARTICLE: Singh P, Singh B, Yedalwar V, et al. Clinico-bacteriological study of vesical calculus. J. Evolution Med. Dent. Sci. 2016;5(36):2131-2137, DOI: 10.14260/jemds/2016/498

\section{INTRODUCTION}

Urinary calculi are the third most common affliction of the urinary tract exceeded only by urinary infection and pathologic condition of the prostate.(1) Bladder stones are the most common manifestation of lower urinary tract lithiasis, currently accounting for $5 \%$ of all urinary stone disease. ${ }^{(2)}$ Exact aetiopathogenesis of stone is still unknown, but Metabolism, Infection, Stasis/Obstruction, Foreign bodies and Malnutrition/Vit. A deficiency has been proved to be a factor behind its formation, no matter where it forms in the body. $(3,4,5,6)$ Presence of upper urinary tract calculi is not necessarily a predisposition to the formation of bladder stones.

Financial or Other, Competing Interest: None.

Submission 22-03-2016, Peer Review 15-04-2016,

Acceptance 21-04-2016, Published 05-05-2016.

Corresponding Author:

Dr. Pushpendra Singh,

21, PG Boys Hostel,

Shyam Shah Medical College,

Rewa,

Madhya Pradesh.

E-mail: pushpendras756@gmail.com

DOI: $10.14260 /$ jemds $/ 2016 / 498$
The incidence of primary bladder calculi in developed countries has been steadily and significantly declining since the $19^{\text {th }}$ century because of improved diet, nutrition and infection control.(7,3) In these countries, vesical calculi affects adults. However, bladder calculi remain common in developing and less developed countries. In these populations, it remains a disease that affects children. Among children, the disease is far more common in boys than girls.(6) The information obtained by bacteriological study of stones and their sensitivity to various drugs not only help in establishing the aetiology, but also useful in planning the treatment and prevention of the recurrence.

\section{Purpose}

Our study was conducted in order to establish the bacteriology of stone and urine in an attempt to evaluate the role of infection in the formation of stones. Associated factors like age, sex, site of infection, obstruction, diet were also evaluated.

\section{MATERIAL AND METHODS}

The present study was carried out in 94 patients of vesical calculi, who were admitted in Surgical Wards of Sanjay Gandhi Memorial Hospital associated with Shyam Shah Medical 
College, Rewa (M. P.) India, during the period from August 2014 to July 2015.

The patients admitted in Surgery Ward with the symptoms of pain in abdomen, burning in micturition, frequency of micturition, dribbling or weak stream of urine, retention of urine, haematuria and other symptoms of uraemia, signs such as distension of bladder or abdominal tenderness were admitted in surgical wards as provisional diagnosed cases of urinary calculus and were subjected to investigations including routine $\mathrm{Hb} \%$, TLC, DLC, RBS, urine analysis, renal function test, X-ray KUB region, USG and intravenous pyelography as and when required.

\section{Investigations}

Following investigations were carried out.

\section{Urine Examination}

- Routine and Microscopic.

\section{Collection of Sample}

- After preliminary cleaning of genitalia by soap and water, the concerned patients were asked to collect clean mid-stream morning samples in sterile culture tubes. Catheterization was only allowed in cases of retention of urine. The specimens of urine thus collected were examined within 1 hour and not more than 6 hours. These culture tubes were sent to pathology department.

- Routine examination: Colour, Albumin and Sugar.

- Microscopic examination: Red blood corpuscles, pus cells, epithelial cells and crystals and casts. Microscopic examination will be done after centrifugation of $1.0 \mathrm{~mL}$ of urine at 1500 R.P.M. Supernatant will be decanted off and one drop of the deposit will be taken on a clean glass slide cover-slip was put over it and examined under low power and higher power field for pus cells, R.B.C, cast and crystals.

\section{Bacteriological Examination}

It was Carried Out in Maximum Number of Cases

a. Direct Smear Examination by Gram staining method.

b. Culture Material Inoculation on MacConkey media or nutrient agar media.

\section{Blood}

Haemoglobin, Total leucocyte count, Differential leucocyte count, Blood urea, Blood sugar and Serum creatinine.

\section{Radiological Examination}

- X-ray KUB region, Ultrasonography and Intravenous pyelography as and when required.

\section{Treatment}

- Surgical Treatment: The patients who were fit for surgery were treated by surgery under local, spinal or general anaesthesia according to their age and comorbid conditions.

- Majority of the cases were subjected to Suprapubic Cystolithotomy alone or in conjunction with suprapubic prostatectomy, in some cases cystoscopic litholapaxy were done, access for any complication and they discharged after suture removal and regular follow-up in surgery OPD.

- The stones removed were grossly examined for number, colour, size, shape and type. Core culture of stone was done.

The core culture technique that we employed involved washing the stone surface with sterile physiological saline, crushing the stone with a sterile hacksaw. The crushed stone core was cultured in $5 \mathrm{~mL}$ thioglycollate broth, which was incubated at room temperature for 18-24 hours and then subcultures were made on blood agar and MacConkey agar plate for isolation of aetiological agent.(8) The isolated organisms were identified by standard techniques.

\section{OBSERVATIONS}

Findings were analysed and following observations were recorded.

\begin{tabular}{|c|c|c|c|c|c|c|}
\hline \multirow{2}{*}{$\begin{array}{l}\text { Sl. } \\
\text { No. }\end{array}$} & \multirow[b]{2}{*}{ Month } & \multirow{2}{*}{$\begin{array}{c}\text { Total No. } \\
\text { of Admission }\end{array}$} & \multirow{2}{*}{$\begin{array}{c}\text { Cases of } \\
\text { Urolithiasis No. }\end{array}$} & \multicolumn{3}{|c|}{ Cases of Vesical Calculi } \\
\hline & & & & Total & $\begin{array}{l}\text { \% Out of Total } \\
\text { Admission }\end{array}$ & $\begin{array}{c}\text { \% Out of Total } \\
\text { Urolithiasis Cases }\end{array}$ \\
\hline 1 & Aug-14 & 723 & 23 & 6 & 0.8 & 26.0 \\
\hline 2 & Sep-14 & 741 & 31 & 17 & 2.3 & 54.8 \\
\hline 3 & Oct-14 & 730 & 20 & 8 & 1.09 & 40.0 \\
\hline 4 & Nov-14 & 673 & 28 & 11 & 1.6 & 39.2 \\
\hline 5 & Dec-14 & 731 & 32 & 14 & 1.9 & 43.7 \\
\hline 6 & Jan-15 & 590 & 19 & 7 & 1.1 & 36.8 \\
\hline 7 & Feb-15 & 679 & 22 & 5 & 0.7 & 26.0 \\
\hline 8 & Mar-15 & 608 & 16 & 3 & 0.4 & 18.75 \\
\hline 9 & Apr-15 & 624 & 22 & 5 & 0.8 & 22.7 \\
\hline 10 & May-15 & 638 & 22 & 8 & 1.2 & 36.3 \\
\hline 11 & Jun-15 & 716 & 17 & 5 & 0.7 & 29.4 \\
\hline 12 & Jul-15 & 836 & 21 & 5 & 0.5 & 23.8 \\
\hline \multicolumn{2}{|c|}{ Total } & 8289 & 279 & 94 & 1.13 & 33.69 \\
\hline
\end{tabular}




\begin{tabular}{|c|c|c|c|c|c|c|c|}
\hline Sl. No. & Age Group (For) & Male & $\mathbf{\%}$ & Female & $\mathbf{\%}$ & Total & \% \\
\hline 1 & $0-10$ & 39 & 44.31 & 2 & 33.33 & 41 & 43.61 \\
\hline 2 & $11-20$ & 10 & 11.36 & 1 & 16.67 & 11 & 11.70 \\
\hline 3 & $21-30$ & 5 & 5.68 & 1 & 16.67 & 6 & 6.38 \\
\hline 4 & $31-40$ & 2 & 2.27 & 0 & 0 & 2 & 2.12 \\
\hline 5 & $41-50$ & 8 & 9.09 & 1 & 16.67 & 9 & 9.57 \\
\hline 6 & $>50$ & 24 & 27.27 & 1 & 16.67 & 25 & 26.59 \\
\hline & Total & $\mathbf{1 0 0}$ & $\mathbf{6}(\mathbf{6 . 3 9 \% )}$ & $\mathbf{1 0 0}$ & $\mathbf{9 4}$ & $\mathbf{1 0 0 \%}$ \\
\hline \multicolumn{2}{r}{} \\
\hline
\end{tabular}

A highest incidence was seen in the age group of $0-10$ (43.61\%), out of these 25 cases from $0-5$ age group and 16 cases were from 6-10 year of age. Youngest patient seen in the study was 2 years old male and the eldest was 82 years male.

\begin{tabular}{|c|c|c|c|}
\hline Sl. No. & Residence & No. of Cases & Percentage \\
\hline 1 & Rural & 87 & 92.55 \\
\hline 2 & Urban & 7 & 7.44 \\
\hline \multicolumn{4}{|c|}{ Table 3: Distribution of Cases According to Residence } \\
\hline \multicolumn{3}{|c}{} \\
\hline
\end{tabular}

\begin{tabular}{|c|c|c|c|}
\hline $\begin{array}{c}\text { Sl. } \\
\text { No. }\end{array}$ & $\begin{array}{c}\text { Socioeconomic } \\
\text { Status }\end{array}$ & $\begin{array}{c}\text { No. of } \\
\text { Cases }\end{array}$ & Percentage \\
\hline 1 & Lower & 83 & 88.29 \\
\hline 2 & Middle & 11 & 11.70 \\
\hline 3 & Upper & 0 & 0 \\
\hline \multicolumn{3}{|c|}{ Table 4: Distribution of Cases According to } \\
Socioeconomic Status \\
\hline
\end{tabular}

\begin{tabular}{|c|c|c|c|}
\hline $\begin{array}{c}\text { Sl. } \\
\text { No. }\end{array}$ & Diet & $\begin{array}{c}\text { No. of } \\
\text { Cases }\end{array}$ & Percentage \\
\hline 1 & Vegetarian & 65 & 69.23 \\
\hline 2 & $\begin{array}{c}\text { Non-Vegetarian } \\
\text { (Occasional) }\end{array}$ & 28 & 29.82 \\
\hline \multicolumn{3}{|c|}{ Table 5: Distribution of Cases According to the Diet } \\
\hline
\end{tabular}

\begin{tabular}{|c|c|c|c|}
\hline $\begin{array}{c}\text { Sl. } \\
\text { No. }\end{array}$ & Symptoms & $\begin{array}{c}\text { No. of } \\
\text { Cases }\end{array}$ & Percentage \\
\hline 1 & Burning micturition & 87 & 92.55 \\
\hline 2 & $\begin{array}{c}\text { Increase frequency of } \\
\text { micturition }\end{array}$ & 83 & 88.29 \\
\hline 3 & Pain in lower abdomen & 80 & 85.10 \\
\hline 4 & Screaming/Strangury & 74 & 78.72 \\
\hline 5 & Dysuria & 54 & 57.44 \\
\hline 6 & $\begin{array}{c}\text { Retention } \\
\text { (Acute+Chronic) }\end{array}$ & $\begin{array}{c}110+8) \\
18\end{array}$ & 19.14 \\
\hline 7 & Haematuria & 12 & 12.76 \\
\hline 8 & Fever & 7 & 7.44 \\
\hline 9 & H/O night blindness & 1 & 1.06 \\
\hline \multicolumn{3}{|c|}{ Table 6: Distribution of Cases } \\
According to the Symptoms \\
\hline \multicolumn{3}{|c|}{} \\
\hline
\end{tabular}

\begin{tabular}{|c|c|c|c|}
\hline $\begin{array}{c}\text { Sl. } \\
\text { No. }\end{array}$ & Associated Illness & $\begin{array}{c}\text { No. of } \\
\text { Cases }\end{array}$ & Percentage \\
\hline 1 & BPH & 18 & 19.14 \\
\hline 2 & PEM & 10 & 10.63 \\
\hline 3 & Hypertension & 08 & 8.51 \\
\hline 4 & Renal calculus & 05 & 5.31 \\
\hline 5 & Stricture Urethra & 04 & 4.25 \\
\hline 6 & Vit. A deficiency & 03 & 3.19 \\
\hline 7 & Rectal prolapsed & 02 & 2.12 \\
\hline
\end{tabular}

\begin{tabular}{|c|c|c|c|}
\hline 8 & $\begin{array}{c}\text { Bladder } \\
\text { diverticulae }\end{array}$ & 02 & 2.12 \\
\hline 9 & Phimosis & 02 & 2.12 \\
\hline 10 & CAD & 02 & 2.12 \\
\hline 11 & Ureteric Calculus & 01 & 1.06 \\
\hline 12 & Hydronephrosis & 01 & 1.06 \\
\hline 13 & Uterine Prolapse & 01 & 1.06 \\
\hline 14 & RPD & 01 & 1.06 \\
\hline \multicolumn{4}{|c|}{ Table 7: Vesical Calculus with Associated Illness } \\
\hline
\end{tabular}

\begin{tabular}{|c|c|c|c|}
\hline $\begin{array}{l}\text { Sl. } \\
\text { No. }\end{array}$ & Clinical Finding & $\begin{array}{l}\text { No. of } \\
\text { Cases }\end{array}$ & Percentage \\
\hline 1 & Suprapubic distension & 10 & 10.63 \\
\hline \multirow{3}{*}{2} & External genitalia & & \\
\hline & (a) Phimosis & 2 & 2.12 \\
\hline & (b) Stricture & 4 & 4.25 \\
\hline \multirow[t]{3}{*}{3} & Rectal Examination & & \\
\hline & $\begin{array}{l}\text { (a) Stone palpable in } \\
\text { bladder }\end{array}$ & 21 & 22.34 \\
\hline & (b) Enlarged prostate & 18 & 19.14 \\
\hline 4 & Bitot's spot & 2 & 2.12 \\
\hline \multicolumn{4}{|c|}{$\begin{array}{c}\text { Table 8: Distribution of Cases According } \\
\text { to Various Clinical Finding }\end{array}$} \\
\hline
\end{tabular}

\begin{tabular}{|c|c|c|c|}
\hline $\begin{array}{c}\text { Sl. } \\
\text { No. }\end{array}$ & $\begin{array}{c}\text { Finding on X-ray KUB } \\
\text { Region }\end{array}$ & $\begin{array}{c}\text { No. of } \\
\text { Cases }\end{array}$ & Percentage \\
\hline 1 & $\begin{array}{c}\text { ROS in Bladder region } \\
\text { alone }\end{array}$ & 83 & 88.29 \\
\hline 2 & ROS in Bladder and Kidney & 5 & 5.31 \\
\hline 3 & ROS in Bladder and urethra & 1 & 1.06 \\
\hline 4 & $\begin{array}{c}\text { ROS in Lower Ureter and } \\
\text { Bladder }\end{array}$ & 1 & 1.06 \\
\hline 5 & ROS on DJ stent in situ & 1 & 1.06 \\
\hline \multicolumn{3}{|c|}{$\begin{array}{c}\text { Table 9: Distribution of Cases According } \\
\text { to Radiological Finding (n=94) }\end{array}$} \\
\hline
\end{tabular}

It is evident from the above table that the opacity in bladder was found in 91 cases (96.80) and 3 cases were diagnosed in USG KUB region.

\section{Distribution of Cases According to USG Finding $(n=52)$}

\begin{tabular}{|c|c|c|c|}
\hline $\begin{array}{c}\text { Sl. } \\
\text { No. }\end{array}$ & $\begin{array}{c}\text { Finding on USG KUB } \\
\text { Region }\end{array}$ & $\begin{array}{c}\text { No. of } \\
\text { Cases }\end{array}$ & Percentage \\
\hline 1 & Vesical calculus alone & 21 & 40.38 \\
\hline 2 & V.C. with BPH & 18 & 34.61 \\
\hline 3 & V.C. with renal calculus & 5 & 9.61 \\
\hline 4 & V.C. with cystitis & 3 & 5.76 \\
\hline 5 & V.C with cystitis with BPH & 2 & 3.84 \\
\hline 6 & V.C. with ureteric calculus & 1 & 1.92 \\
\hline 7 & V.C. with hydronephrosis & 1 & 1.92 \\
\hline 8 & V.C with RPD & 1 & 1.06 \\
\hline
\end{tabular}

It is evident from above table that USG KUB revealed calculus in $100 \%$ cases $(n=52)$ 


\begin{tabular}{|c|c|c|c|c|}
\hline $\begin{array}{c}\text { Sl. } \\
\text { No. }\end{array}$ & \multicolumn{2}{|c|}{ Investigations } & $\begin{array}{l}\text { No. of } \\
\text { Cases }\end{array}$ & Percentage \\
\hline \multirow{2}{*}{1} & \multirow{2}{*}{$\mathrm{Hb} \%$} & $<10$ & 72 & 76.56 \\
\hline & & $>10$ & 22 & 23.04 \\
\hline \multirow{3}{*}{2} & \multirow{3}{*}{ Blood Urea } & $20-40$ & 79 & 84.04 \\
\hline & & $41-60$ & 14 & 14.89 \\
\hline & & $>60$ & 01 & 1.06 \\
\hline \multirow{3}{*}{3} & \multirow{3}{*}{$\begin{array}{l}\text { Serum } \\
\text { Creatinine }\end{array}$} & $0.5-1.2$ & 84 & 89.36 \\
\hline & & $1.3-2.0$ & 09 & 9.57 \\
\hline & & $>2.0$ & 01 & 1.06 \\
\hline \multirow[b]{2}{*}{4} & \multirow{2}{*}{$\begin{array}{l}\text { Random } \\
\text { Blood } \\
\text { Sugar }\end{array}$} & $<140$ & 91 & 96.81 \\
\hline & & $>140$ & 03 & 3.19 \\
\hline \multicolumn{5}{|c|}{$\begin{array}{l}\text { Table 10: Distribution of Cases } \\
\text { According to Blood Investigation }\end{array}$} \\
\hline
\end{tabular}

It is evident from the above table that the $23.04 \%$ patients were anaemic, blood urea was raised in $15.95 \%$ cases and serum creatinine was raised in $10.63 \%$ cases, blood sugar was raised in $3.19 \%$ cases.

\begin{tabular}{|c|c|c|c|}
\hline Sl. No. & PUS Cell/HPF & No. of Cases & Percentage \\
\hline 1 & $<6$ & 54 & 62.79 \\
\hline 2 & $7-10$ & 24 & 27.90 \\
\hline 3 & Loaded & 8 & 9.30 \\
\hline \multicolumn{3}{|c|}{ Table 11: Distribution of Cases According } \\
to Microscopic Examination of Urine (n=86) \\
\hline
\end{tabular}

It is evident from the above table that the UTI was present in $37.2 \%$ cases.

\begin{tabular}{|c|c|c|c|}
\hline $\begin{array}{l}\text { Sl. } \\
\text { No. }\end{array}$ & Bacteria Grown & $\begin{array}{l}\text { No. of } \\
\text { Cases }\end{array}$ & Percentage \\
\hline 1 & E. Coli & 16 & 19.04 \\
\hline 2 & Klebsiella aerogenes & 3 & 3.57 \\
\hline 3 & Mixed & 3 & 3.57 \\
\hline 4 & Proteus & 2 & 2.38 \\
\hline 5 & $\begin{array}{c}\text { Staphylococcus } \\
\text { aureus }\end{array}$ & 1 & 1.19 \\
\hline 6 & Pseudomonas & 1 & 1.19 \\
\hline 7 & Sterile & 58 & 69.04 \\
\hline
\end{tabular}

\begin{tabular}{|c|c|c|c|}
\hline $\begin{array}{l}\text { Sl. } \\
\text { No. }\end{array}$ & Bacteria & $\begin{array}{l}\text { No. of } \\
\text { Cases }\end{array}$ & Percentage \\
\hline 1 & E. Coli & 13 & 18.57 \\
\hline 2 & Klebsiella aerogenes & 2 & 2.85 \\
\hline 3 & $\begin{array}{c}\text { Staphylococcus } \\
\text { aureus }\end{array}$ & 2 & 2.85 \\
\hline 4 & Proteus & 1 & 1.42 \\
\hline 5 & Sterile & 52 & 74.28 \\
\hline & 70 & 100.00 \\
\hline \multicolumn{4}{|c|}{$\begin{array}{c}\text { Table 13: Distribution of Cases According to Core } \\
\text { Culture of Stone }(n=70)\end{array}$} \\
\hline
\end{tabular}

\section{DISCUSSION}

The present study "Clinicobacteriological Study of Vesical Calculus" was carried out in 94 patients of vesical calculus who were admitted in Surgical Wards of Sanjay Gandhi Memorial Hospital associated with Shyam Shah Medical College, Rewa, during the period from Aug 2014 to July 2015. Vesical calculus has been one of the most common and distressing maladies of mankind. Since the ancient times and are still with us affecting the patients of all age group, sex and socioeconomic status, although incidence varies in different groups.
Even after extensive research on various aspects no definite aetiological factor is known. Recurrence and its management is still a great problem.

Dietary analysis in cases of vesical calculus gives information about various properties of different foods. Some are calculogenic, while the others are helpful in preventing this by various ways. This information may be of use in decreasing the incidence and specially recurrence of stones.

The bacteriological analysis of vesical calculus and urine, impart the information regarding the urinary tract infection in calculus formation.

\section{Incidence}

In present study, the incidence of vesical calculus in relation to total admission and total urolithiasis cases was $1.13 \%$ and $33.69 \%$ respectively

In the past 50 years the incidence of vesical calculi in developed countries has declined significantly, but underdeveloped/developing nations still suffer from endemic bladder calculi.

\section{Age Incidence}

In the present series $43.61 \%$ cases of vesical calculus belongs to age group $0-10$ years, out of these 25 (26.55\% of total) cases were belong to 0-5 years' age group. The second highest incidence was seen in $>50$ years of age group $(26.59 \%)$. The youngest patient seen in the study was 2 years of male and oldest was 82 years of male. The findings are conformity with the study of S.G. Kabra et al (1972), Shakya G.R. (1996) and Tiwari et al (2000) who reported that the maximum incidence of vesical calculus is below 10 years of age. Pathogenesis of bladder calculi is likely complex with multiple contributing lithogenic factor, in adult (mainly men over 50 years) outlet obstruction is the main aetiological factor, BPH being the most common cause. The causes of bladder stone formation in children Vit. A deficiency/malnutrition (diet low in animal proteins, which consists mainly cereals), other factors include dehydration, fever, diarrhoea, infection and metabolic abnormality.

\section{Sex Incidence}

In the present series male constituted about $93.61 \%$ cases of vesical calculus as compared to $6.38 \%$ female. Male-to-female ratio was $14.6: 1$. This is nearly similar to the finding of $\mathrm{M}$. Singh (2003), S. Singh et al (1992) who reported male-tofemale ratio 12:1 and 9:1 respectively.

The study indicates that disease is mainly prevalent in male. The higher incidence of vesical calculus in males in comparison to female may be due to increased serum testosterone level, which favours increased endogenous oxalate production by liver which in turn predisposes to oxalate stone formation. Moreover, increased urinary citrate concentration in females may help in protection against urolithiasis.

\section{Residence/Diet/Socioeconomic Group}

In present study $92.55 \%$ cases belonged to rural area, while only $7.45 \%$ cases were urban; $69.23 \%$ cases were pure vegetarian and only $30.77 \%$ cases were non-vegetarian (Occasional). Majority of cases (88.29\%) belonged to low socioeconomic status and $11.71 \%$ cases belonged to middle class and no case belonged to upper class. 
In present study, factors appearing to be responsible for vesical calculus are- Vitamin A deficient diet, imbalance diet, diet low in protein, carbohydrate rich diet, low phosphate diet, cheap and easily available food rich in oxalic acid, poor hygiene, lack of knowledge and delay in seeking medical help.

\section{Clinical Features Symptoms}

In present study, pain in lower abdomen was seen in $85.10 \%$ cases and it could have been due to associated chronic retention of urine and urinary tract infection. Pain usually due to movement of stone, irritating the trigone of bladder in vesical calculus, while ureteric and renal colic is attributed to higher intraluminal pressure due to distension. Burning micturition $(92.55 \%)$ is almost always associated with urinary tract infection. Retention of urine (19.14\%) was due to stone obstructing the outflow and enlarged prostate.

Screaming (pulling of prepuce in male or labia in female) was present in $78.72 \%$ cases. Screaming is because of irritation of trigone that stimulate the second and third sacral nerves to the scrotum and third and fourth sacral nerve to perineum. Vitamin A deficiency was present in 3 Cases, one had history of night blindness and Bigot's spot was seen during ophthalmic examination in 2 cases.

\section{Physical Signs}

In the present series main physical signs were stone palpable in bladder (22.34\%), enlarge prostate $(19.14 \%)$ in per rectal examination.

Suprapubic distension (10.63\%) - distended bladder was seen in either impacted urethral or impacted vesical calculus or enlarged prostate with associated vesical calculus.

Stricture urethra was present in 4 cases and phimosis was seen in 2 cases.

\section{Associated Illness}

BPH, PEM and Hypertension were common associated illness with vesical calculus.

\section{Radiological Finding}

In present study, plain X-ray KUB region revealed calculus in bladder region in $91(96.80 \%)$ cases. In 3 cases ROS was not seen either obscured by overlying bowel gas shadows or not radiopaque. In 84 cases radio opacity was seen in bladder region alone. Radio-opacity associated with kidney in 5 cases, one case in urethra and one case in ureter. In one case radioopacity was seen on DJ stent in situ in bladder. In 10 cases, multiple stones were seen in UB region. Present study indicates that the X-ray KUB region is the main diagnostic tool, non-radiopaque urinary bladder stone can be detected by USG KUB region; 18 cases of $\mathrm{BPH}, 5$ cases of cystitis and one case of bilateral hydronephrosis diagnosed in USG KUB region.

\section{Blood Investigation}

In present study, $23.04 \%$ patients were anaemic. Blood urea was raised in $15.95 \%$ cases and serum creatinine was raised in $10.63 \%$ cases. Blood sugar was raised in $3.19 \%$ cases. In $45-$ year-old female diagnosed as vesicle calculus with $\mathrm{B} / \mathrm{L}$ hydronephrosis with uterine prolapsed had blood urea 89 $\mathrm{mg} / \mathrm{dL}$ and serum creatinine was $5.14 \mathrm{mg} / \mathrm{dL}$. The above investigations were carried as and when required. These abnormalities were corrected prior to surgical management.
In the present series, urine in the majority of cases $(86.17 \%)$ was found to be acidic. Alkaline $\mathrm{pH}$ is because of infection with urease producing bacteria (Proteus, strepto, staph). Phosphate calculi mainly develop in alkaline urine and oxalate, both in acidic and alkaline.

\section{Urine Microscopic and Culture}

In the present series, urinary tract infection was present in $37.2 \%$ cases. The culture was positive in 26 cases out of 84 cases (30.95\%). In 23 cases single organism was identified and in 3 cases mixed organism were found.

\section{Surgical Procedures for Bladder Stones}

In present study, all cases were managed surgically. Suprapubic cystolithotomy was done and associated disease as enlarged prostate, phimosis, stricture urethra was also operated in same settings.

Bladder calculi were mainly treated by suprapubic cystolithotomy (97.8\%). In 14 cases, SPCL with prostatectomy $(14.89 \%)$ and in 3 case SPCL with bladder neck dilation was done. In one case where stone was present in urethra, it was first pushed into the bladder followed by suprapubic cystolithotomy. In 2 cases cystoscopic litholapaxy was done. In 2 cases, circumcision and in 4 cases urethral dilatation was done along with SPCL.

\section{Number of Stones}

Out of the 91 cases operated in the present series, most of them 81 cases $(89.01 \%)$ had single stone. In 10 cases $(10.98 \%)$ multiple stones were present.

\section{Gross Examination of Stone}

In present study, size (maximum length) of maximum stones was $3-4 \mathrm{cms}$ (42.69\%). In $22.2 \%$ cases size of stone was 4 to 5 $\mathrm{cm}, 5.61 \%$ cases it was $5-7 \mathrm{~cm}$. The explanation for large stone may be due to ignorance, late presentation of symptom, lack of knowledge because of low socioeconomic status and type of calculus as phosphate calculi remains asymptomatic.

Maximum size of stone removed was $9 \times 7 \mathrm{~cm}$ weighing 460 gms. Maximum number of stone had rough surface (76.4\%), dirty white colour (84.26\%) and oval in shape (80.89).

\section{Complications}

In the present series, most of the patients were free of complications. The common postoperative complications were suprapubic urinary leakage (4.39\%), wound infection (3.29\%), wound gapping (2.19\%), catheter blockade (2.19\%) and haematuria $(1.09 \%)$.

Suprapubic urinary leakage was associated with suprapubic cystolithotomy; possible contributing factors were the presence of urinary tract infection, wound infection, catheter blockade and accidental early removal of urethral catheter. All the cases of urinary leakage were treated conservatively. Wound infection was associated with comorbid condition like anaemia, diabetes and treated by dressing and proper antibiotic.

In present study, there was no mortality.

\section{Core Culture of Stone}

Bacteriological study of stone removed from bladder (Core culture of stone) was performed in 70 cases in present study. 
Culture was positive in 18 cases (25.71\%). E. coli were seen in majority of the cases (18.57\%); while Staphylococcus aureus (2.85\%), Klebsiella aeruginosa (2.85\%) and Proteus (2.5\%) In 52 cases core culture was sterile.

Similar observation has been noted by R. Kumar (1980), Shigetta M (1993) and M. Singh (2003).

The explanation for the presence of bacteria within the calculi may be due to recurrent urinary tract infection, insignificant intermittent bacteraemia from where the bacteria are excreted in bladder and may act as a nidus for deposition of crystals either by damaging the mucous coat or perhaps also by acting as a nidus for crystallization of salts. ${ }^{(9)}$ Thus, a vicious cycle starts, the infection leading to stone formation and then the stone causing infection. $(8,10)$ Most of the current literature on the subject focuses on pathogenesis of infectious urinary stones. Griffith et al showed that bacterial urease is a primary cause of infection stones. The bacteriological study of urine and stone samples revealed that commonest pathogens were E. coli, Klebsiella aerogenes, Staphylococcus and Proteus spp. E. coli is not a urease producing organism and is not considered to be a stone producing micro-organism. However, the present study revealed that E. coli was predominant microorganism recovered from core of stones.

\section{Hospital Stay}

In majority of cases hospital stay was up to 10 days, average hospital stay was 11.67 days. Average hospital stay in SPCL alone was 10.30 days, in SPCL with prostatectomy was 15.57 days, in SPCL with bladder neck dilatation was 11.3 days and in cystoscopic litholapaxy was 3.5 days.

Postoperative longer stay was because of complication like wound infection, wound gap, abnormal investigation and poor general condition.

\section{SUMMARY AND CONCLUSION}

The present study "Clinicobacteriological Study of Vesical Calculus" was carried out in 94 patients of vesical calculus who were admitted in Surgical Wards of Sanjay Gandhi Memorial Hospital associated with Shyam Shah Medical College, Rewa, during the period from Aug 2014 to July 2015.

After admitting the patients, detailed history was recorded systematically including presenting complaints, history of urinary tract infection and history of night blindness. Detailed general and systemic examination was carried out with special emphasis on genitourinary system. Routine investigations were done, special investigation like urine culture and core culture of stone was done to find out aetiological factors. Treatment was planned and patients were operated accordingly. Patients were followed up for any complications during the hospital stay.

Relevant Literature was Reviewed, Observations were Systematically Recorded, Critically Analysed and Following Conclusions Were Made

1. Incidence of vesical calculus was $1.13 \%$ out of total surgical admissions and $33.69 \%$ out of total urolithiasis cases.

2. Maximum number of patients (43.61\%) was in the age group 0-10 year. The second highest incidence (26.59\%) was seen in $>50$ years of age group. Youngest patient was 2 years of male and eldest patient was 82 years of male.
3. Males predominated the females with male-to-female ratio was 14.6:1.

4. Majority of cases were from low socio-economic income group (88.29\%).

5. Majority of cases were from rural areas $92.55 \%$.

6. Majority of cases were vegetarian (69.23\%).

7. Most common symptom was burning in micturition (92.55\%) followed by increased frequency of micturition (88.29\%). Pain in lower abdomen (85.10\%) and screaming (78.72\%).

8. BPH, PEM and Hypertension were common associated illness with vesical calculus.

9. Plain X-ray KUB revealed calculus in urinary bladder region in 91 (96.80\%) cases. In 3 cases, ROS was not seen either obscured by overlying bowel gas shadows or not radiopaque. USG KUB revealed calculus in $100 \%$ cases $(\mathrm{n}=52)$.

10. Anaemia was present in $23.04 \%$ cases, blood urea was raised in $15.95 \%$ cases and serum creatinine was raised in $10.63 \%$ cases and 3 patients were Diabetic.

11. Majority of cases reaction of urine was acidic $(86.17 \%)$ and in $(13.82 \%)$ it was alkaline.

12. Urinary tract infection was present in $37.2 \%$ cases. Majority of cases urine culture was positive (30.95\%). E. coli was the commonest organism (19.04\%) followed by Klebsiella aerogenes (3.57\%), proteus (2.38\%), Staphylococcus aureus (1.19\%), pseudomonas (1.19\%) and mixed organism was found in $3.3 \%$ cases.

13. Bladder calculi were mainly treated by suprapubic cystolithotomy (97.8\%). In 14 cases SPCL with prostatectomy (14.89\%) and in 3 cases SPCL with bladder neck dilation was done. In one case where stone was present in urethra; it was first pushed into the bladder followed by suprapubic cystolithotomy. In 2 cases cystoscopic litholapaxy was done. In 2 cases circumcision and in 4 cases urethral dilatation was done along with SPCL.

14. In majority of cases single stone was found (89.01\%). In 10 cases multiple stones were removed. Size (maximum length) of maximum stones was 3-4 cms. Maximum number of stones had rough surface(76.4\%), dirty white colour $(84.26 \%)$ and oval in shape (80.89)

15. Maximum size of stone removed was $9 \times 7 \mathrm{~cm}$ weighing 460 gms.

16. Commonest complication in the postoperative period was suprapubic urinary leakage (4.39\%), wound infection (3.29\%), wound gap $(2.19 \%)$, catheter blockade (2.19\%) and haematuria (1.09\%)

17. Core culture of stone was positive in 18 cases (25.71\%). E. coli was the predominant organism (18.57\%) followed by Staphylococcus aureus (2.85\%), Klebsiella (2.85\%) and proteus $(2.5 \%)$.

18. In majority of cases hospital stay was up to 10 days, average hospital stay was 11.67 days.

It is concluded from above study that vesical calculus are common in children of low socioeconomic status. Metabolism, infection, stasis/outlet obstruction, foreign body and malnutrition/vitamin A deficiency remained the important factors in its formation. They are commonly diagnosed by Xray KUB. However, in places where cystoscopy is available it is the choice both for diagnostic and therapeutic purposes. 
Suprapubic cystolithotomy is the most common intervention in present scenario. E. coli is the predominant organism found both in urine and core culture of stone. There is significant association regarding the presence of vesicle calculi and the development of urinary infections. Incidence of vesical calculus is progressively decreasing in urban region because of improved diet, nutrition, infection control and modification of lifestyle.

\section{REFERENCES}

1. Wein Alan J. Campbell walsh urology. Elsevier 2016;11 th edn.

2. Onkawa M, Tokunaga S, Nakashima T, et al. Composition of urinary calculi related to urinary tract infection. J Urol 1992;148(3 Pt 2):995-997.

3. Schwartz BF, Stoller ML. The vesical calculus. Urol clin North Am 2000;27(2):333-346.
4. Forland M. Urinary tract infection. How has its management changed? Postgraduate Medicine 1993;93(5):71-86.

5. Parivar F1, Low RK, Stoller ML. The influence of diet on urinary stone disease. American J Urol 1996;155(2)432440.

6. Otnes B. Correlation between causes and composition of urinary stones. Scand J Urol Nephro 1983:17(1):93-98.

7. Sarica K, Baltaci S, Kilic S, et al. 371 bladder calculi in a benign prostatic hyperplasia patient. Int Urol Nephro 1994;26(1):23-25.

8. Brockis JG, Bowyer RC, Mc CUllock RK. Pathophysiology of endemic bladder stones. Litteton : PGS 1981;p.3-18.

9. Sutor DJ, Wooley SE, Illingworth JJ. Some aspects of adult urinary stone problem in Great Britain and Northern Ireland. Br J Urol 1974;46(3):275-288.

10. Parks JH, Coe FL. The financial effects of kidney stone prevention. Kidney int 1996;50(5):1706-1712. 